\title{
Effect of Piperine on Cypermethrin-induced Oxidative Damage in Rats
}

\author{
Palanisamy Sankar, Avinash G Telang* and Ayyasamy Manimaran \\ Division of Pharmacology and Toxicology, Indian Veterinary Research Institute, Izatnagar - 243122, Bareilly, Uttar Pradesh, India
}

\begin{abstract}
Cypermethrin is a synthetic pyrethroid insecticide used worldwide in agriculture, home pest control and as an ectoparasiticide in animals. The aim of the present study was to investigate the ability of piperine, a natural alkaloid compound, to attenuate subacute cypermethrin-induced changes in serum biochemical markers and lipid peroxidation, and alteration in antioxidant enzyme activity in the liver and kidney of rats. The rats were divided into five groups of six each; the first group served as control and second group was used as vehicle control. While, groups III, IV and V were orally treated with piperine (50 mg/kg body weight), cypermethrin ( $25 \mathrm{mg} / \mathrm{kg} \mathrm{body} \mathrm{weight)}$ and cypermethrin plus piperine, respectively for 28 days. Cypermethrin administration caused elevated levels of biochemical markers in serum and lipid peroxidation in liver and kidney. While the activities of non-enzymatic and enzymatic antioxidants levels were decreased except superoxide dismutase in liver and kidney. Administration of piperine along with cypermethrin significantly decreased the level of lipid peroxidation and significantly increased the reduced glutathione, catalse and glutathione peroxidase level both in liver and kidney. The results indicate that piperine ameliorate the cypermethrin-induced biochemical alterations and oxidative damage in rats.
\end{abstract}

Keywords: Cypermethrin; Piperine; Oxidative stress; Antioxidants; Rats

Abbreviations: CYP: Cypermethrin; ALT: Alanine Amino Transferase; AST: Aspartate Amino Trandferase; BUN: Blood Urea Nitrogen; GSH: Reduced Glutathione; LPO: Lipid Peroxidation; SOD: Superoxide Dismutase; GPx: Glutathione Peroxidase

\section{Introduction}

Cypermethrin (CYP) is a synthetic pyrethroid with potent insecticidal property. It is being used worldwide in agriculture, home pest control, protection of food stuff and disease vector control $[1,2,3]$. CYP can be found in trace amounts or at higher concentrations in soil and air. CYP is more hydrophobic in nature and its target site is biological membrane [4]. In mammals, CYP can accumulate in body fat, skin, liver, kidneys, adrenal glands, ovaries, lung, blood, and heart $[5,6]$. Populations at highest risk of high dose exposure are producers, hygienic and pesticide workers, and small farm owners applying CYP for plant protection; exposure to low dose originates mainly from the household application of insecticides, contaminated food and water [7]. Several studies have shown that pyrethroid toxicity is linked to different mechanisms, including reactive oxygen species generation and oxidative stress $[8,9]$. The reactive oxygen species directly react with cellular biomolecules; damage lipids, proteins and DNA in cells ultimately leading to cell death. It is now being realized that one of the reasons for CYP toxicity is imbalance between amount of free radicals generated and antioxidant defenses in the body.

During the past few years, estimation of free radical generation and antioxidant defense has become an important aspect of investigation in mammals. Some studies have shown that antioxidant such as, Vitamin E, isoflavones and L-ascorbic acid prevent the oxidative damage due to CYP induced toxicity in rats $[10,11,12]$. Plant products are known to exert their protective effects by scavenging free radicals and modulating antioxidant defense system. Piperine, an alkaloid, found in long pepper (Piper longum Linn.) and black pepper (Piper nigrum Linn.). The compound has many pharmacologic activities such as antioxidant, bioenhancer, anti-inflammatory and hepatoprotective effects $[13,14,15,16]$. Vijayakumar et al. [17] found that simultaneous supplementation of black pepper or piperine along with high fat diet lowered thiobarbituric acid reactive substances and maintained superoxide dismuatase, catalase, glutathione peroxidase, and reduced glutathione levels to near those of control rats. Earlier studies from various laboratories have proved the antioxidant and hepatoprotecive activity of piperine against benzo(a) pyrene and aflatoxin-induced toxicity in mice and rats [18]. Therefore, the present study was undertaken to evaluate the antioxidant effect of piperine against CYP-induced oxidative stress in rats.

\section{Materials and Methods}

\section{Animals}

The study was conducted in adult male Wistar rats (6-8 weeks, 100-120 g) obtained from the Laboratory Animals Resources Section of the Institute. Rats were maintained under standard management conditions. The rats were given standard rat feed and water ad libitum throughout the experiment. All the animals were quarantined for a period of at least 7 days before beginning of the experiment. The rats were handled and the study was conducted in accordance with the Institute Animal Ethics Guidelines.

\section{Chemicals}

Cypermethrin (CYP; 96\%) was a kind gift from Gharda Chemicals, Mumbai. Piperine was purchased from M/s Sigma Chemicals, USA. All other chemicals used were of analytical grade from E. Merck, Germany and India; Sigma Chemicals, USA and SRL Chemicals, India.

\section{Dose selection}

CYP was dissolved in ground nut oil and administered orally for

${ }^{*}$ Corresponding author: Dr. A. G. Telang, Senior Scientist, Division of Pharmacology and Toxicology, Indian Veterinary Research Institute, Izatnagar 243122, Bareilly, Uttar Pradesh, India, Tel: 91-581-2300291; Fax: 91-581-2302188; E-mail: agtelang@rediffmail.com

Accepted December 15, 2010; Published December 18, 2010

Citation: Sankar P, Telang AG, Manimaran A (2011) Effect of piperine on cypermethrin-induced oxidative damage in rats. J Veterinar Sci Technol 2:105. doi:10.4172/2157-7579.1000105

Copyright: $\odot 2011$ Sankar P, et al. This is an open-access article distributed under the terms of the Creative Commons Attribution License, which permits unrestricted use, distribution, and reproduction in any medium, provided the original author and source are credited. 


\begin{tabular}{|l|l|l|l|l|}
\hline Treatment & Dose & AST (Units/mL) & ALT (Units/mL) & BUN $(\mathbf{m g} / \mathbf{d L})$ \\
\hline Control & - & $64.14 \pm 1.29$ & $32.28 \pm 1.44$ & $16.21 \pm .29$ \\
\hline Groundnut oil & $1 \mathrm{ml} / \mathrm{kg}$ & $66.23 \pm 2.93$ & $33.37 \pm 2.25$ & $15.74 \pm .38$ \\
\hline Piperine & $50 \mathrm{mg} / \mathrm{kg}$ & $63.9 \pm 1.65$ & $30.07 \pm 2.28$ & $15.94 \pm .65$ \\
\hline Cypermethrin & $25 \mathrm{mg} / \mathrm{kg}$ & $92.19 \pm 3.14^{\mathrm{a}}$ & $73.19 \pm 3.12^{\mathrm{a}}$ & $19.22 \pm .89^{\mathrm{a}}$ \\
\hline Cypermethrin+ Piperine & $25 \mathrm{mg} / \mathrm{kg}+50 \mathrm{mg} / \mathrm{kg}$ & $76.582 \pm .76^{\mathrm{b}}$ & $42.78 \pm 3.62^{\mathrm{b}}$ & $0.62 \pm .03$ \\
\hline
\end{tabular}

Table 1: Effect of piperine treatment on cypermethrin-induced alteration on rat serum biomarkers.

28 days, at a dose rate of $25 \mathrm{mg} / \mathrm{kg}$ body weight/day (1/10 of LD50) [19] by oral gavage. Piperine was dissolved in ground nut oil and given orally for 28 days, at a dose rate of $50 \mathrm{mg} / \mathrm{kg}$ body weight/day. Piperine was administered one hour prior to CYP treatment.

\section{Experimental design}

Rats were divided into five groups containing six animals each. Group I (control), was given normal saline, while Groups II was given once equivalent amount of ground nut oil (1\%: Vehicle control). Group III was administered CYP ( $25 \mathrm{mg} / \mathrm{kg}$, orally) daily for 28 days. Group IV was administered piperine $(50 \mathrm{mg} / \mathrm{kg}$, orally) daily for 28 days. Group V was administered piperine $(50 \mathrm{mg} / \mathrm{kg}$, orally) and then CYP ( $25 \mathrm{mg} / \mathrm{kg}$, orally) daily for 28 days. All the rats were observed daily for clinical signs of toxicity during the entire period of the study. Rats were sacrificed at the end of the exposure period. Blood was collected from heart in a dry, clean and sterilized test tube for serum separation. The sera samples were preserved at $-20^{\circ} \mathrm{C}$ until analysis. Liver and kidney were excised, washed with ice cold normal saline and used for the assay of oxidative stress parameters.

\section{Serum biochemical assay}

The activity of alanine amino transferase (ALT), aspartate amino transferase (AST) and level of blood urea nitrogen (BUN) and creatinine were determined spectrophotometrically, according to the manufactures protocol (Span Diagnostics Ltd; India).

\section{Assessment of oxidative stress and antioxidant enzyme activity}

Estimations of different oxidative stress-related biochemical parameters were carried out in liver and kidney. An amount of $200 \mathrm{mg}$ of liver and kidney was separately taken in $2 \mathrm{ml}$ of ice-cold phosphate buffer saline $\mathrm{pH}$ 7.4. Another $200 \mathrm{mg}$ of sample was separately taken in $2 \mathrm{ml}$ of $0.02 \mathrm{M}$ ethylene diamine tetra acetic acid for reduced glutathione (GSH) estimation. The homogenates $(10 \%)$ prepared with homogenizer (IKA, Germany) under ice-cold condition were centrifuged for $10 \mathrm{~min}$ at $3000 \mathrm{rpm}$. The supernatant was stored at $-20^{\circ} \mathrm{C}$ until assay of different oxidative stress-related parameters.

Lipid peroxidation (LPO) was evaluated in terms of malondialdehyde (MDA) production [20]. An antioxidant status was assessed by evaluating both the nonenzymatic and enzymatic antioxidative defense systems in liver and kidney homogenate. The level of reduced glutathione (GSH), a nonenzymatic antioxidant, was determined by estimating free-SH groups, using 5-5' dithiobis 2nitrobenzoic acid (DTNB) following the method of Sedlak and Lindsay [21]. Catalase activity was assayed by the method as described by Aebi [22]. The activity of superoxide dismutase (SOD) was measured as per the method of Madesh and Balasubramanian [23]. Glutathione peroxidase (GPx) activity was determined by the method of Paglia and Valentine [24]. The protein content was estimated by the method of lowry et al. [25] using bovine serum albumin as standard.

\section{Statistical analysis}

Data have been expressed as mean \pm SEM. The change in CYP mediated effects was compared from the control values, while CYP plus piperine mediated alterations were compared to CYP group. Statistical analysis of data was performed using GraphPad InStat software. Data were analyzed by ANOVA and means were compared with Tukey multiple comparison test. A value of $p<0.05$ was considered statistically significant.

\section{Results}

\section{Effects on serum biomarkers}

CYP administration significantly increased the activities of ALT and AST in serum as compared to control (Table 1). Piperine treatment significantly restored the activity of ALT and AST. The levels of BUN and creatinine in serum were significantly elevated after CYP exposure (Table 1). Oral administration of piperine along with CYP caused significant reduction in CYP-induced changes in BUN and creainine. There were no differences in any of parameters between the water and vehicle control group; therefore, all comparisons are made to the water control.

\section{Effects on lipid peroxidation}

CYP exposure produced significant adverse effects on the redox status of liver and kidney, as evidenced by a significant increase in MDA level (Figure 1) as compared to control. Oral supplementation of piperine along with CYP resulted in significant decrease in LPO level as compared to CYP treated rats.

\section{Effects on antioxidative glutathione system}

Effects on the GSH and GPx in liver and kidney are presented in Figure 2 (A and B). CYP treatment significantly decreased GSH and GPx activity in the liver and kidney tissues of rats. Simultaneous treatment with CYP and piperine caused significant increase in GSH and GPx activity in both the tissues as compared to rats treated with CYP alone.

\section{Effects on the activities of SOD and catalase}

The activities of SOD and catalase in liver and kidney of CYP exposed rats are show in Figure 3 (A and B). CYP exposure resulted in significant elevation in SOD activity in liver and kidney as compared to control. However, the activities of catalase in both the tissues were significantly decreased. Daily oral administration of piperine along with CYP in rats significantly restored the SOD and catalase activities almost equal to control.

\section{Discussion}

The present study evaluated the effect of piperine on CYPinduced oxidative damage in rat liver and kidney. CYP exposure produces a large amount of reactive oxygen species and reactive nitrogen species that can impair cellular antioxidant defense systems and simultaneously damage the cellular components such as lipids, 


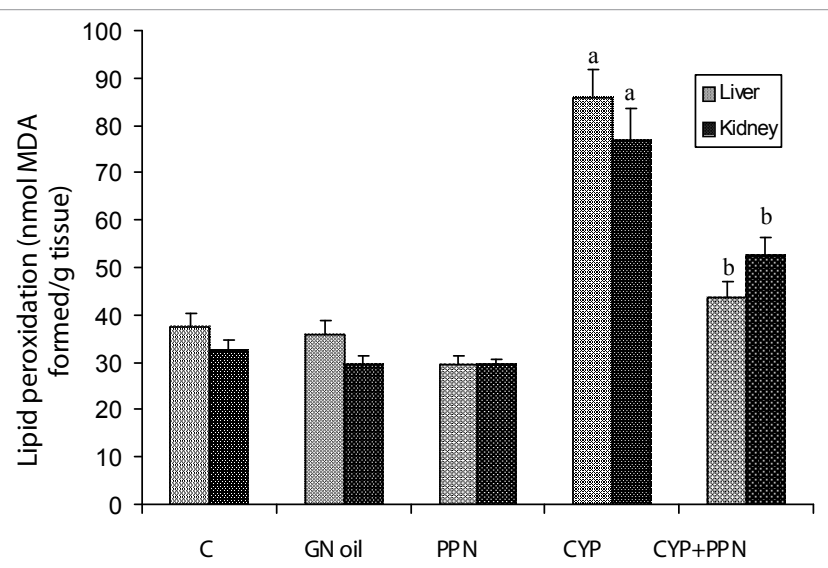

Figure 1: Effects of 28 days oral administration of CYP, PPN and CYP plus PPN on lipid peroxidation level of liver and kidney in male rats. Each bar represents mean \pm SE of 6 rats. Significant differences are indicated by superscript a compared t o control, superscript b compared to CYP group. C: control, GN oil: ground nut oil PPN: piperine, CYP: cypermethrin, PPN at $50 \mathrm{mg} / \mathrm{kg}$ and CYP at $25 \mathrm{mg} / \mathrm{kg}$.
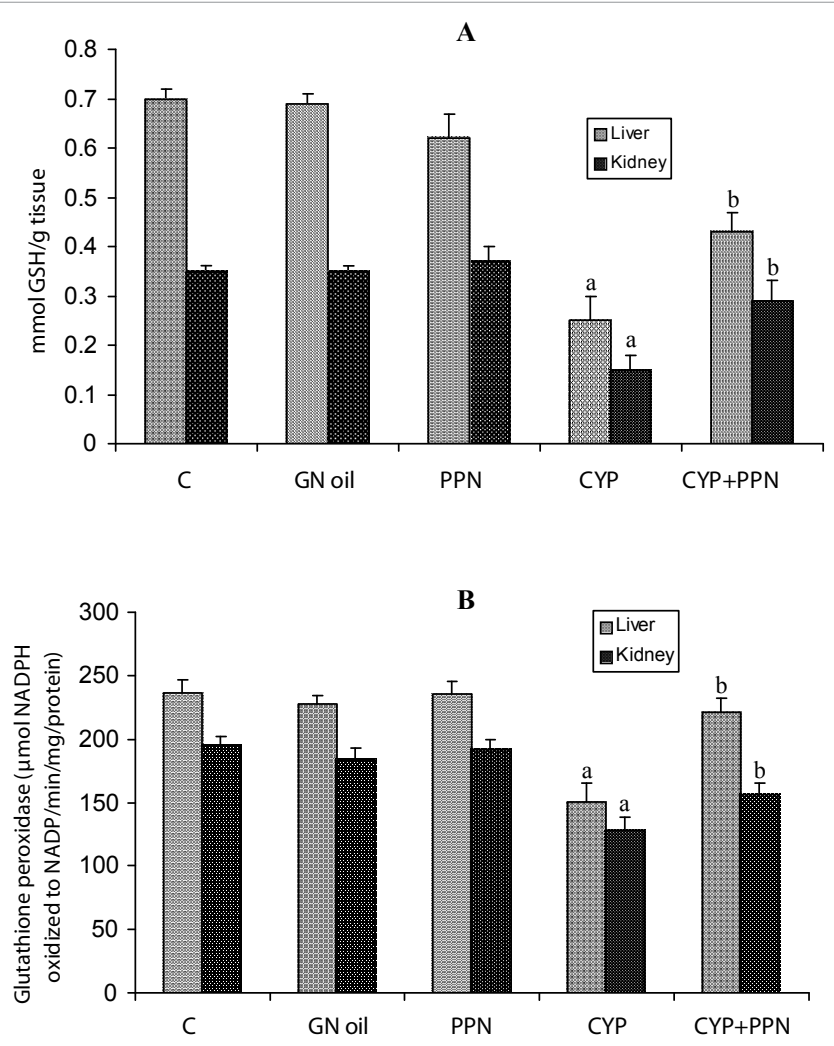

Figure 2: Effects of 28 days oral administration of CYP, PPN and CYP plus PPN on reduced glutathione $(A)$ and glutathione peroxidase $(B)$ of liver and kidney in male rats. Each bar represents mean \pm SE of 6 rats. Significant differences are indicated by superscript a compared to control, superscript $\mathbf{b}$ compared to CYP group. C: control, GN oil: ground nut oil PPN: piperine, CYP: cypermethrin, PPN at $50 \mathrm{mg} / \mathrm{kg}$ and CYP at $25 \mathrm{mg} / \mathrm{kg}$.

proteins, and DNA. In the present study, we observed that CYP administration induced oxidative stress in rat liver and kidney as evidenced by many antioxidant markers and that this effect could be prevented by treatment with piperine. In the present study, CYP treatment induced a high degree of lipid peroxidation in the liver and kidney tissue of the rats due to the susceptibility of the both the tissues towards oxidative damage. Several studies have indicated that, there is increase in the intracellular levels of reactive oxygen species and oxidative stress in CYP-induced toxicity $[8,28]$. LPO has been shown to cause profound alterations in the structure and functions of the cell membrane, including decreased membrane fluidity and increased membrane permeability [31]. The increased AST and ALT activities as showed in the present study could be due to the oxidative damage by free radicals in liver tissue. AST is normally found in a various tissues including liver, heart, muscle, kidney, and brain. It is released into serum when any one of these tissues is damaged. ALT is, by contrast, normally found largely concentrated in liver and is released into the bloodstream as the result of liver injury. The increase in serum AST and ALT activities as observed in present study is in agreement with the findings of Yousef et al. [11]. According to Awad et al. [26] cell damage exhibit good correlation with the enzyme leakage. The results of present study indicate that treatment with CYP caused significant increase in serum creatinine and BUN. An abnormally elevated serum creatinine level is more specific and sensitive indicator of impaired kidney function. Similar changes in creatinine and BUN values were reported in rabbits due to CYP toxicity [5].

Antioxidant enzymes are considered to be the first line of cellular defense against oxidative damage. GST and GPx two antioxidant enzymes, which counteract free radical generation. [27]. The decrease in the activities of GST and GPx due to the generation of reactive oxygen species leads to enhancement in lipid peroxidation.. A significant reduction in GSH and GPx levels in liver and brain
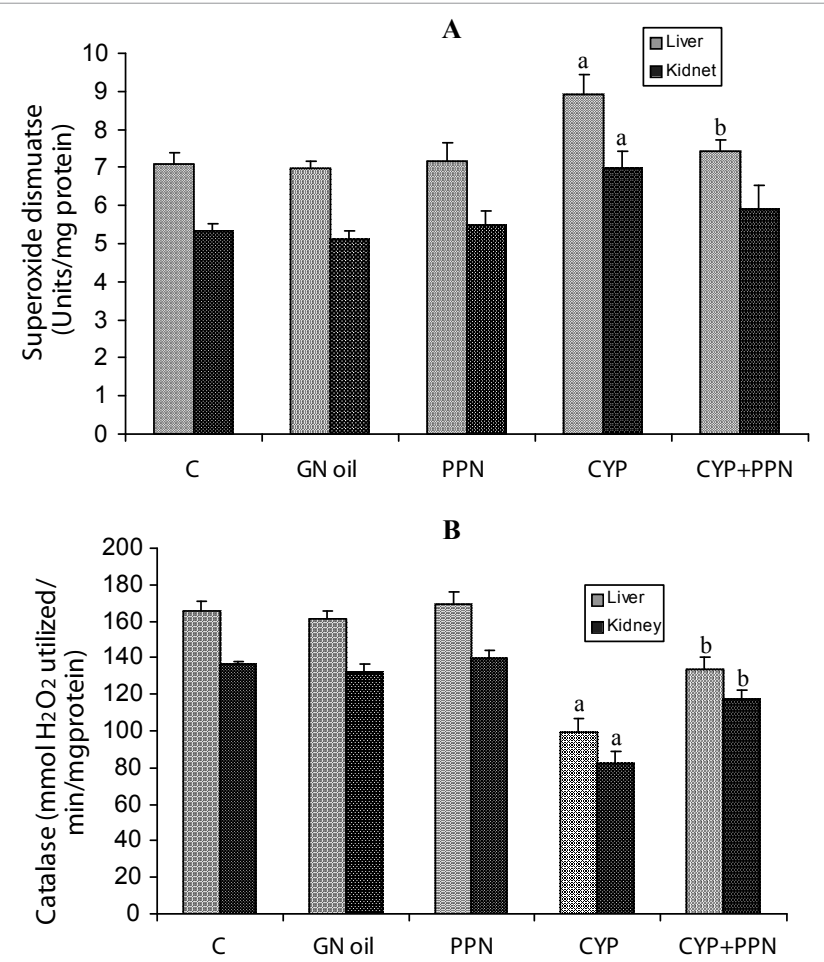

Figure 3: Effects of 28 days oral administration of CYP, PPN and CYP plus PPN on superoxide dismutase (A) and catalase (B) level of liver and kidney in male rats. Each bar represents mean \pm SE of 6 rats. Significant differences are indicated by superscript a compared to control, superscript b compared to CYP group. C: control, GN oil: ground nut oil PPN: piperine, CYP: cypermethrin, PPN at $50 \mathrm{mg} / \mathrm{kg}$ and CYP at $25 \mathrm{mg} / \mathrm{kg}$. 
tissues [28] and depletion of GSH and GPx in erythrocytes after dermal exposure of CYP in rats have been reported [29]. SOD is an antioxidant metalloenzyme that reduce superoxide radicals to water and molecular oxygen. The increase in SOD activity in liver and kidney of CYP exposed rats may be due to the compensatory adaptive mechanism of the antioxidant system to combat the increased ROS generation by the CYP toxicity [8]. Catalase is a haemoprotein, which reduces hydrogen peroxide to molecular oxygen and water. Reduction of catalase activity in CYP treated rats may be due to the enhanced production of hydrogen peroxide. Furthermore, it has been suggested that LPO might be a contributing factor for decrease in the catalase activity during cypermethrin toxicity [10].

The results of present study show that piperine treatment attenuated CYP-induced alteration in serum markers enzyme, LPO levels, and concomitantly restored enzymatic and non-enzymatic antioxidants in the rat kidney and liver. Piperine has been shown to inhibit the lipid peroxidation $[30,13]$. The direct antioxidant activity of piperine against various free radicals, hydroxyl as well as superoxide, was explored under in vitro conditions by Mittal and Gupta [32]. The suppressive action of piperine on lipid peroxidation observed in in vivo experiments suggests that piperine may have direct effect on membranes which may decrease the susceptibility of the membranes to lipid peroxides. GSH is presumed to be an important endogenous defense against the peroxidative destruction of cellular membranes. Tissue GSH concentration reflects the potential for detoxification. The simultaneous treatment with piperine elevated the CYP-induced decrease in the levels of GSH. Earlier studies revealed that piperine supplementation prevents depletion of reduced glutathione and total thiols in the liver [33]. In the present study, levels of catalase and GPx in liver and kidney of cypermethrin plus piperine-treated rats were significantly elevated and the SOD levels were maintained equal to that of control group. There is extensive evidence that supplementation of piperine enhance or restore the enzymatic and non enzymatic antioxidant enzymes [34]. It was observed that oral supplementation of piperine in rats fed high fat diet resulted in lowering of LPO level and SOD, catalase, GPX, and GSH levels maintained close to control rats [17]. The mechanism of action of piperine may involve scavenging or eliminating the free radicals like hydroxyl radical, superoxide radical and singlet oxygen and activate on gene responsible for antioxidant enzymes [18]. In conclusion, the results of present study suggest that oral treatment with $50 \mathrm{mg} / \mathrm{kg}$ of piperine significantly decreases the CYP-induced oxidative damage in rats.

\section{Acknowledgments}

The Junior Research Fellowship awarded to the first author by the Indian Council of Agricultural Research (ICAR), New Delhi is gratefully acknowledged. The authors are thankful to the Director, Indian Veterinary Research Institute, for providing necessary facilities.

\section{References}

1. Hutson DH, Gaughan LC, Casida JE (1981) Metabolism of the cis- and transisomers of cypermethrin in mice. Pesticide Science 12: 385-398.

2. Soderlund DM, Bloomquist JR (1989) Neurotoxic actions of pyrethroid insecticides. Annual Review Entomology 34: 77-96.

3. Velisek J, Wlasow T, Gomulka P, Svobodova Z, Dobsikova R, et al. (2006) Effects of cypermethrin on rainbow trout (Oncorhynchus mykiss). Veterinarni Medicina 51: 469-476.

4. Michelangeli F, Robson MJ, East JM, Lee AG (1990) The conformation of pyrethroids bound to lipid bilayers. Biochim Biophys Acta 1028: 49-57.
5. Hall BE, Vickers JA Hopkins JA (1980) A study to determine the bioaccumulation of $14 \mathrm{C}$-cypermethrin radioactivity in the rat following repeated oral administration. WHO, Report No.2487-72/20.

6. Manna S, Bhattacharyya D, Mandal TK, Das S (2004) Repeated dose toxicity of alfa-cypermethrin in rats. J Vet Sci 5: 241-245.

7. Gorell JM, Johnson CC, Rybicki BA, Peterson EL, Richardson RJ (1998) The risk of parkinsons disease with exposure to pesticides, farming, well water and rural living. Neurology 50: 1346-1350.

8. Kale M, Rathore N, John S, Bhatnagar D (1999) Lipid peroxidative damage on pyrethroid exposure and alterations in antioxidant status in rat erythrocytes: a possible involvement of reactive oxygen species. Toxicol Lett 105: 197-205.

9. Gupta A, Nigam D, Gupta A, Shukla GS, Agarwal AK (1999) Effect of pyrethroidbased liquid mosquito repellent inhalation on the blood-brain barrier function and oxidative damage in selected organs of developing rats. J Appl Toxicol 19: $67-72$

10. Atessahin A, Yilmaz S, Karahan I, Tasdemir B (2005) The effect of Vitamin-E and selenium on cypermethrin induced oxidative stress in rats. Turkish Journal of Veterinary and Animal Science 29: 385-391.

11. Yousef MI, El-Demerdash FM, Kamel KI, Al-Salhen KS (2003) Changes in some hematological and biochemical indices of rabbits induced by isoflavones and cypermethrin. Toxicology 189: 223-234

12. Raina R, Verma PK, Pankaj NK, Kant V, Prawez S (2009) Protective role of L-ascorbic acid against cypermethrin-induced oxidative stress and lipid peroxidation in Wistar rats. Toxicology and Environmental Chemistry 1-7.

13. Selvendiran K, Sakthisekaran D (2004) Chemopreventive effect of piperine on modulating lipid peroxidation and membrane bound enzymes in benzo(a) pyrene induced lung carcinogenesis. Biomedicine \& Pharmacotherapy 58: 264 267.

14. Nirala SK, Bhadauria M, Mathur R, Mathur A (2008) Influence of alphatocopherol, propolis and piperine on therapeutic potential of tiferron against beryllium induced toxic manifestations. J Appl Toxicol 28: 44-54.

15. Kumar S, Singhal V, Roshan R, Sharma A, Rembhotkar GW, et al. (2007) Piperine inhibits TNF- $\alpha$ induced adhesion of neutrophils to endothelia monolayer through suppression of NF-KB and IKB kinase activation. Eur Pharmacol 575: 177-186.

16. Matsuda H, Ninomiya K, Morikawa T, Yasuda D, Yamaguchi I, et al. (2008) Protective effects of amide constituents from the fruit of Piper chaba on Dgalactosamine/TNF- $\alpha$-induced cell death in mouse hepatocytes. Bioorganic \& Medicinal Chemistry Letters 18: 2038-2042.

17. Vijayakumar RS, Surya D, Nalini N (2004) Antioxidant efficacy of black peppe (Piper nigrum $\mathrm{L}$ ) and piperine in rats with high fat diet induced oxidative stress. Redox Report 9: 105-110

18. Selvendiran K, Vijeya Singha JP, Krishnan KB, Sakthisekaran D (2003) Cytoprotective effect of piperine against benzo[a]pyrene induced lung cance with reference to lipid peroxidation and antioxidant system in Swiss albino mice. Fitoterapia 74: 109-115

19. Cantalamessa F (1993) Acute toxicity of two pyrethriod; permethrin and cypermethrin in neonatal and adult rats. Arch toxicology 67: 510-513.

20. Shafiq-ur-Rehman, Rehman S, Chandra O, Abdulla M (1994) Evaluation of malondialdehyde as an index of lead damage in rat brain homogenates. Biometals 8: 275-279.

21. Sedlak J, Lindsay RH (1968) Estimation of total, protein-bound and nonprotein sulfydryl groups in tissue with Ellman's reagent. Anal Biochem 25: 192-205.

22. Aebi H (1983) Catalase. In Bergmeyer, HU (ed.). Methods Enzymology, pp. 276-286, Academic Press, New York, USA.

23. Madesh M, Balasubramanian KA (1998) Microtitre plate assay for superoxide dismutase using MTT reduction by superoxide. Indian J Biochem Biophys 35 184-188.

24. Paglia DE, Valentine WN (1967) Studies on the quantitative and qualitative characterization of erythrocyte glutathione peroxidase. J Lab Clin Med 70: 158169

25. Lowry OH, Rosebrough NJ, Farr AL, Randall RJ (1951) Protein measurement with the Folin-Phenol reagent. J Biol Chem 193: 265-275.

26. Awad ME, Abdel-Rahman MS, Hassan SA (1998) Acrylamide toxicity in isolated rat hepatocytes. Toxicology In Vitro 12: 699-704. 
Citation: Sankar P, Telang AG, Manimaran A (2011) Effect of piperine on cypermethrin-induced oxidative damage in rats. J Veterinar Sci Technol 2:105. doi:10.4172/2157-7579.1000104

Page 5 of 5

27. Franco R, Schoneveld OJ, Pappa A, Panayiotidis MI (2007) The central role of glutathione in the pathophysiology of human diseases. Arch Physiol Biochem 113: 234-258.

28. Giray B, Gurbay A, Hincal F (2001) Cypermethrin-induced oxidative stress in rat brain and liver is prevented by Vitamin $\mathrm{E}$ or allopurinol. Toxicology letters 3: 139-146.

29. Raina R, Verma PK, Pankaj NK, Prawez S (2009) Induction of oxidative stress and lipid peroxidation in rats chronically exposed to cypermethrin through dermal application. Journal of Veterinary Science 10: 257-259.

30. Rauscher FM, Sanders RA, Watkins JB (2000) Effects of piperine on antioxidant pathways in tissues from normal and streptozocin-induced diabetic rats. J Biochem Mol Toxicol 14: 329-334.
31. Selvendiran K, Sakthisekaran D (2004) Chemopreventive effect of piperine on modulating lipid peroxidation and membrane bound enzymes in benzo(a) pyrene induced lung carcinogenesis. Biomedicine \& Pharmacotherapy 58: 264 267.

32. Mittal R, Gupta RL (2000) In vitro antioxidant activity of piperine. Methods Find Exp Clin Pharmacol 22: 271-274.

33. Koul IB, Kapil A (1993) Evaluation of the liver protective potential of piperine, an active principle of black and long peppers. Planta Med 59: 413-417.

34. Dhuley JN, Raman PH, Mujumdar AM, Naik SR (1993) Inhibition of lipid peroxidation by piperine during experimental inflammation in rats. Indian J Exp Biol 31: 443-445. 